\title{
An optimization approach towards air traffic forecasting: A case study of air traffic in Changi airport
}

\author{
T. Sailauov, Z.W. Zhong* \\ Mechanical and Aerospace Engineering, Nanyang Technological University, Singapore.
}

\begin{abstract}
South-East Asia is considered one of the fastest air traffic growing regions in the world. Congested air traffic and weather conditions have thus become major factors in air traffic management. In this paper the model for air traffic forecasting was able to forecast the country, city-pair and airport-pair air traffic. Results show that the passenger forecasting for Singapore has dependence not only on that country but on neighbouring countries as well. The paper predicts that the passenger movements in Changi airport will increase up to 81.65 million people by year 2023, which is $31.23 \%$ more than that in 2017. Also, the number of passenger aircraft between Singapore and Jakarta city-pair will increase up to 34702 by year 2023, which is $26.6 \%$ more than that in 2017. In addition, the number of passenger aircraft between Changi airport and KLIA airport-pair will be between 31698 and 40311 by year 2023.
\end{abstract}

Keywords air traffic, forecasting, optimization model, GDP; city-pair, airport-pair

DOI: $10.19139 /$ soic.v7i1.372

\section{Introduction}

Forecasting of the air traffic is an essential part of any project planning. The project success heavily depends on the accuracy of the forecasting. That is why accurate air traffic forecasting is needed for the aviation industry.

In general air traffic forecasting models are divided into 2 categories: macroscopic models and microscopic models [4]. Macroscopic models aim to forecast air traffic in a whole region or country or a city. On the other hand, microscopic models aim to forecast air traffic between city pairs or regions only. Also, depending on explanatory variables used, forecasting models can be divided into geo-economic factors and service-related factors. Geoeconometric factors can be location-based factors and economic factors like GDP. Usually, these factors are out of airline control. Service-related factors are airline dependant factors, like the quality of service and airfare price. In this paper, a macroscopic model with geo-economic factors has been implemented which uses the microscopic method of forecasting as a base. The model shows the relationship between city-pair air traffic and country air traffic.

The future of air traffic is unknown, but it is essential to have an idea of air traffic in order to plan current projects. Efficient ATFM relies on accurate air traffic forecasting [5]. Also, Ak?a shows that by analyzing future passenger demand, air traffic network performance and accessibility of the waypoints can be evaluated [2]. Air traffic forecasting has been an important topic since 1970 [3]. Initially, air traffic forecasting was done using linear or quadratic models, but they were not able to predict accurately. Lately, correlation between GDP and air traffic has been discovered. Using this finding, researchers developed econometric models, which use GDP as the biggest parameter to estimate air traffic [22]. Past researches have shown that there is a need for liberalization of air traffic

\footnotetext{
${ }^{*}$ Correspondence to: Tolebi Sailauov (Email: tolebi002@e.ntu.edu.sg). Mechanical and Aerospace Engineering, Nanyang Technological University. 988 Jurong West st 93, Singapore (640988).
}

ISSN 2310-5070 (online) ISSN 2311-004X (print)

Copyright (C) 2019 International Academic Press 
and adopting an open sky concept [9]. These methods might help to increase competitiveness and increase the efficiency of airspace. In addition, Hazledine suggests that forecasting air traffic of passenger flights on city-pair routes depends on many factors [11].

\section{Literature review}

In the forecasting area, many different models have been proposed. Some researchers used a neural network approach as in [21], and some researchers used support vector machines [25] to determine air traffic. Wenzel, S. et al [23] proposed a model which forecasts air traffic movements taking into account airport capacity. The model consists of 5 steps. However, it has a lot of assumptions in each step. Gravio, G. et al. [7] used time series to forecast safety performance of the air traffic. It is done by estimating the number of occurrences of each event. However, it is very difficult to have an accurate database for it.

Meanwhile, Jenatabadi and Ismail [12] conducted the research on the impact of economic situations on airline performance. It was done using a triangular model, and by considering internal operations. They addressed the three most common gaps in estimating performance, by using a latent variable instead of the measurement variable. Their research concluded that the economic status of the country plays an important role in planning, decision and strategy making.

There have been many ways of forecasting air traffic $[19,18]$. There has been researching on air traffic forecasting based on Time Series Models with Aggregated and Disaggregated Approaches in Spain [14]. Hazledine [11] used a gravity model of trade to forecast air traffic. However, treating passengers as trade between countries did not produce promising results. Some researchers proposed forecasting air traffic congestion status instead of normal forecasting to evaluate air traffic situation [26]. It was done by using fuzzy C-means and support vector machine. Similarly, Athina states that Madrid-Barajas planners forecasted air traffic in Madrid-Barajas airport using Spain GDP only [17]. However, it might be insufficient and can lead to unnecessary deviation. These were points which motivated the development of the proposed model. Also, there is a probabilistic method proposed by researchers in NASA [15]. This method estimates probability distribution function of aircraft passing a particular point. However, probability distribution function was estimated based on each individual aircraft probability of passing that point. If large number of aircraft is considered, the resulting cumulative error can be large too.

In the past, many researchers and organizations proved that there is a correlation between GDP and air traffic [16]. ICAO has been using worldwide GDP to estimate world traffic in [1]. However, their model would not be able to represent some specific airspace or country air traffic accurately. That is why this paper proposes an econometric model combined with optimization to increase accuracy of the air traffic forecasting.

\section{Metholodoly}

In order to accurately forecast air traffic, historical data have been obtained, and investigation of the past forecasting models has been done. There have been different models proposed in the past starting from linear models till using GDP data to forecast air traffic. However, based on the studied literature review, an optimization has not been used for air traffic forecasting, especially in Singapore. Optimization helps to find a specific model for the specific country to forecast air traffic accurately.

One of the ways to examine airport congestion is to determine the number of aircraft movements or passenger movements in the airport. Similarly, to examine airspace congestion is to determine the number of aircraft movements in the airspace. The mathematical model was developed in order to calculate it. General formulas of this model are:

$$
N A M_{j}=\sum_{k \in \text { other countries }} N A M_{j k},
$$




$$
\begin{gathered}
N A M_{j k}=\frac{N P F_{j k}}{L F A S}+C F_{j k} \\
N P F_{j k}=A G D P_{j}^{x} G D P_{k}^{y}+l \text { year }+m \\
C F_{j k}=B e_{j}^{z_{1}} e_{k}^{z_{2}}+r
\end{gathered}
$$

$N A M_{j}$ is a number of aircraft movements in airport $\mathrm{j} . N A M_{j k}$ is a number of aircraft movements between $\mathrm{j}$ and k. $N P F_{j k}$ is a number of passengers flying between $\mathrm{j}$ and $\mathrm{k} . L F$ is a load factor [1], which is a ratio of passengerkilometres travelled to seat-kilometres available. $A S$ is an aircraft size, which is a ratio of total seats offered to total number of aircraft. $C F_{j k}$ is a number of cargo flights between $\mathrm{j}$ and $\mathrm{k} . e_{j}$ and $e_{k}$ are the export of goods (millions of USD) of country $\mathrm{j}$ and $\mathrm{k}$ respectively. $A, B, C, D, r, l$ and $m$ are constants to be found by optimization program. Formula (1) calculates the number of aircraft movements in airport j. It can be seen that the number of aircraft movements in airport $\mathrm{j}$ is equal to the sum of the number of aircraft movements between $\mathrm{j}$ and $\mathrm{k}$ (other countries). Formula (2) gives the formula of how to calculate a number of aircraft movements between 2 countries. They are equal to a number of passengers flying between those 2 countries divided by load factor and aircraft size [1], plus cargo flights in between. As it is shown in [1], air traffic depends on GDP of the countries. Formula (3) shows how a number of passengers flying between 2 countries are calculated. This formula is proposed based on fact that traffic between 2 countries is related to GDP of these countries. That is why general formula dependent on GDP has been proposed, where coefficients have to be found by optimization program.

Similarly, when $\mathrm{j}=\mathrm{k}$, number of domestic flights can be calculated from Formula (2). Formula (2) shows that a number of domestic aircraft movements in $\mathrm{j}$ is equal to the number of passengers in domestic flights divided by load factor and aircraft size plus cargo flights in country $\mathrm{j}$. The model proposes to find cargo flight movements between $\mathrm{j}$ and $\mathrm{k}$ to be found by Formula (4). When $\mathrm{j}=\mathrm{k}$, Formula (4) can be used for calculation of internal cargo flights.

The traffic on specific air routes can be found with help of these formulas. Assuming airport $\mathrm{j}$ has w numbers of air routes from 1 to $\mathrm{w}$. Let the number of aircraft movements in airport $\mathrm{j}$ using air route a to be $N A M_{a j}$. Then $\sum_{a=1}^{w} N A M_{a j}=N A M_{j}$.

If we assume that the ratio of $N A M_{j}$ to $N A M_{a j}$ to be: $\frac{N A M_{j}}{N A M_{a j}}=p_{1}+p_{2} t$, where $p_{1}$ and $p_{2}$ are constants. Then the number of flights on the air route a of airport $\mathrm{j}$ can be found by formula:

$$
N A M_{a j}=\frac{N A M_{j}}{p_{1}+p_{2} t}
$$

$N A M_{j}$ can be found by Formula (1). $p_{1}$ and $p_{2}$ can be found from historical data. These general formulas can be applied to any country. Using formula (3), number of passengers movements to airport $\mathrm{j}$ can be found:

$$
N A M_{j}=G D P_{j}^{x}\left(\sum_{i \in \text { other countries }} B_{i} G D P_{i}^{y}\right)+m
$$

Due to the limitation of available data, formula (1) can be simplified. Instead of using all other countries GDP data, some flight movements can be simplified as:

$$
N A M_{j} \approx G D P_{j}^{x}\left(\sum_{i \in \text { some countries }} B_{i} G D P_{i}^{y}\right)+l \text { year }+m
$$

In order to apply this model to Changi airport, the number of countrys GDP which was used for the model is restricted to be 8 . They are Singapore, Indonesia, Malaysia, Philippines, Australia, China, Thailand, and India. Singapore does not have domestic flights, which is why domestic flights have not been considered. Formula (8) shows how number of passenger movements in Changi airport can be calculated. 


$$
\begin{aligned}
N A M_{S G}=G D P_{S G}^{x}\left(B_{C N} G D P_{C N}^{y}+\right. & B_{T H} G D P_{T H}^{y}+B_{I N} G D P_{I N}^{y}+B_{A U} G D P_{A U}^{y}+ \\
& \left.+B_{P H} * G D P_{P H}^{y}+B_{M Y} * G D P_{M Y}^{y}\right)+l(\text { year }-1997)+m .
\end{aligned}
$$

Here $x, y, B, l$ and $m$ are variables which will be found through optimization program in such a way that software minimizes sum of squared errors. Optimization program used for this calculation is CPLEX. GDP values of Singapore and its neighbour countries are given in [8]. These values were used for formulas from (1) to (8). Then testing on 2010-2014 data has been done, followed by the forecasting of the Singapore air traffic from 2018 to 2023. In addition, data on aircraft movements, air freight movements and aircraft movements in Singapore are given in [24].

\section{Modelling}

First of all, there is a need to determine if the proposed methodology can produce valid results. In order to do that, air traffic data from 1999 to 2019 have been used to forecast air traffic, and data from 2010 to 2015 have been used to validate. There are 8 models proposed which consider different number of inputs. The first model uses formula (8), where the GDPs of Singapore, Malaysia, Indonesia, Philippines, Australia, China, Thailand, and India have been used to find a number of passenger movements in Singapore. The second model is a simplified version of the first model, where the least impactful country has been eliminated from the model. Similarly, other models are simplified versions of the previous models, where the least significant impact giving country has been eliminated. The least significant impact giving country for air traffic forecasting of Singapore has been determined by looking at the coefficients of each contributor (B values), as shown in Table 3. The smaller the value of the contributor, the less significant it is.

Figure 1 shows the structure of the forecasting model proposed in this chapter. Firstly, all the countries with high traffic flow need to be determined. The number of countries can be from 5 to 10 . For example, if the country that is going to be forecasted is Singapore, then the top busiest route countries might be Malaysia, Indonesia, Thailand, Philippines, China, Australia and India. After that, past traffic data and GDP data have to be collected.

Secondly, the model coefficients can be determined using CPLEX. Each country in each model has its own B coefficient. Using these coefficients, the optimal model can be determined. After that, future air traffic can be forecasted using forecasted GDP values. These values can be extracted from different sources, for example, from World Bank website. More details are given in the results and discussion section.

\section{Case study 1: Forecasting passenger movements in Changi airport}

Firstly, the simulation has been done using data from 1999 to 2009. Average error, maximum error, and RMS (root mean square) error of forecasting for years 2010 to 2015 have been found to be $2.84 \%, 7.82 \%$, and $3.79 \%$ respectively. These errors (below $10 \%$ ) are considered to be acceptable for forecasting. Hence, proposed methodology was applied to the prediction of passenger movements in Singapore. Passenger movements in Changi airport has been forecasted using 8 different models. Numbers of variables have been decreased 1 by 1 . It was done by eliminating the least important variables. In Figure 2, model 1 is a model with all GDP data, model 2 is a model with all GDP data excluding GDP of China, model 3 is a model with all GDP data excluding GDP of China and India. Model 4 is a model with all GDP data excluding GDP of China, India and Indonesia. Model 5 is a model with all GDP data excluding GDP of China, India, Indonesia and Australia. Model 6 is a model with GDP data from Singapore, Malaysia, Thailand and linear model. Model 7 is a model with GDP data from Singapore, Thailand and linear model. Model 8 is a linear model. The coefficients ( $B$ values, $x, y, l, m)$ of the model are computed using 


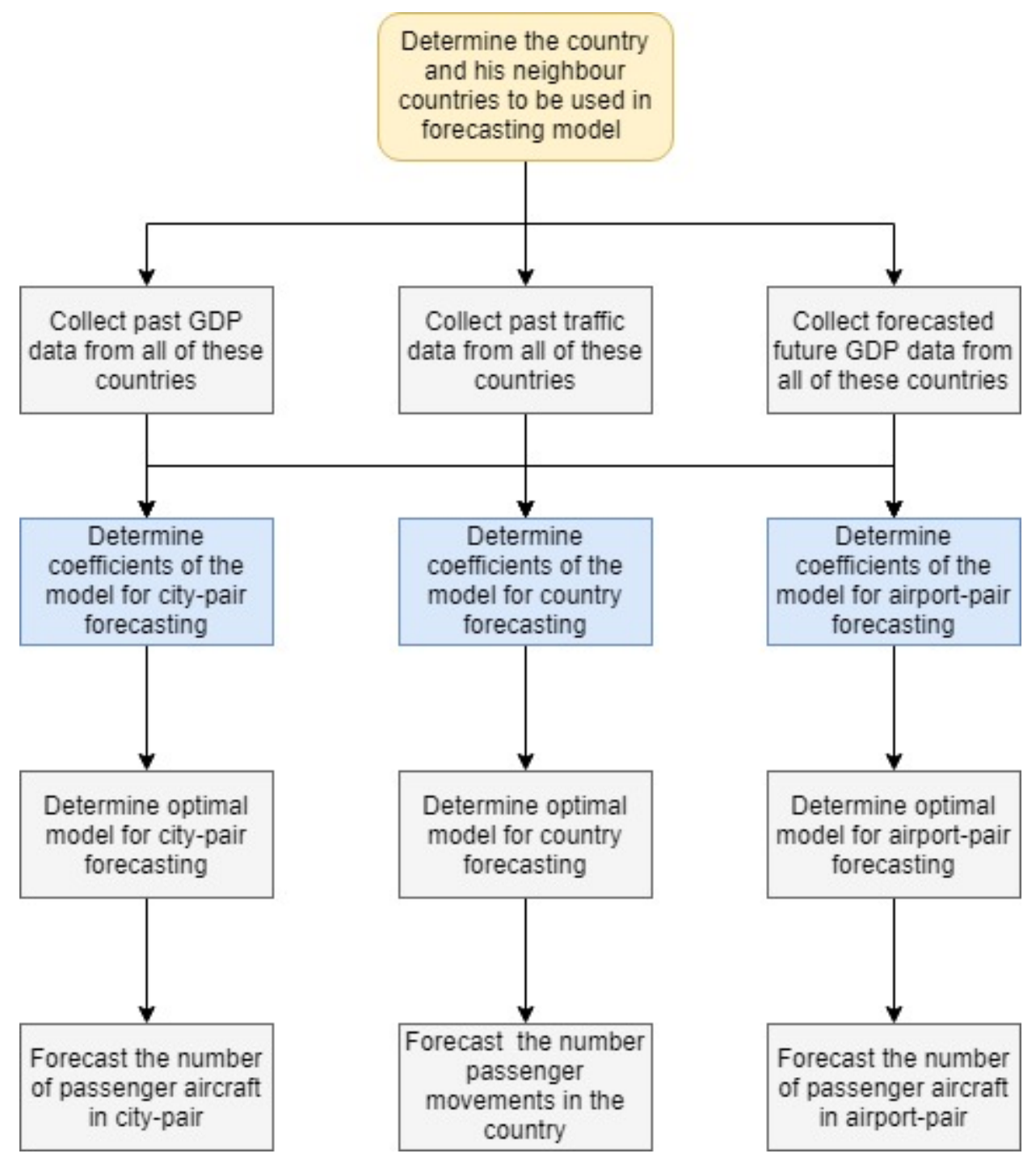

Figure 1. The structure of the forecasting model

CPLEX. These coefficients have been calculated in such a way that CPLEX minimizes objective function:

$$
\text { Min } \sum_{\text {year }=1998}^{2017}(\text { year }-1997)(\text { error }[\text { year }])^{2}
$$

Historical data of older years usually have less importance compared to recent years. Therefore, the objective function uses the prioritized least sum of square errors, instead of the least sum of square errors.

After running simulation using all data, we can see that $B_{\text {China }}$ has the smallest absolute value among all $B$ values. Therefore, GDP of China has been dropped for the second simulation. In the third simulation, GDP of India has been dropped because $B_{\text {India }}$ has the smallest absolute value among $B$ values in the second simulation. Similarly, GDP of the country with the lowest $B$ value is dropped in each of the following simulation until the model becomes linear.

Each $B$ value represents the level of significance of a particular country. The smallest absolute B value for model 1 is $B_{\text {China }}$. It means that GDP value of China does not affect Singapore air traffic as much as GDP values of other 
countries considered in the case study. After that, real values of passenger movements in Changi airport and values from 8 models have been compared for years 1998 to 2017. Figure 2 shows graphical representation of passenger movement values for Changi airport from 1998 to 2017 using 8 models.

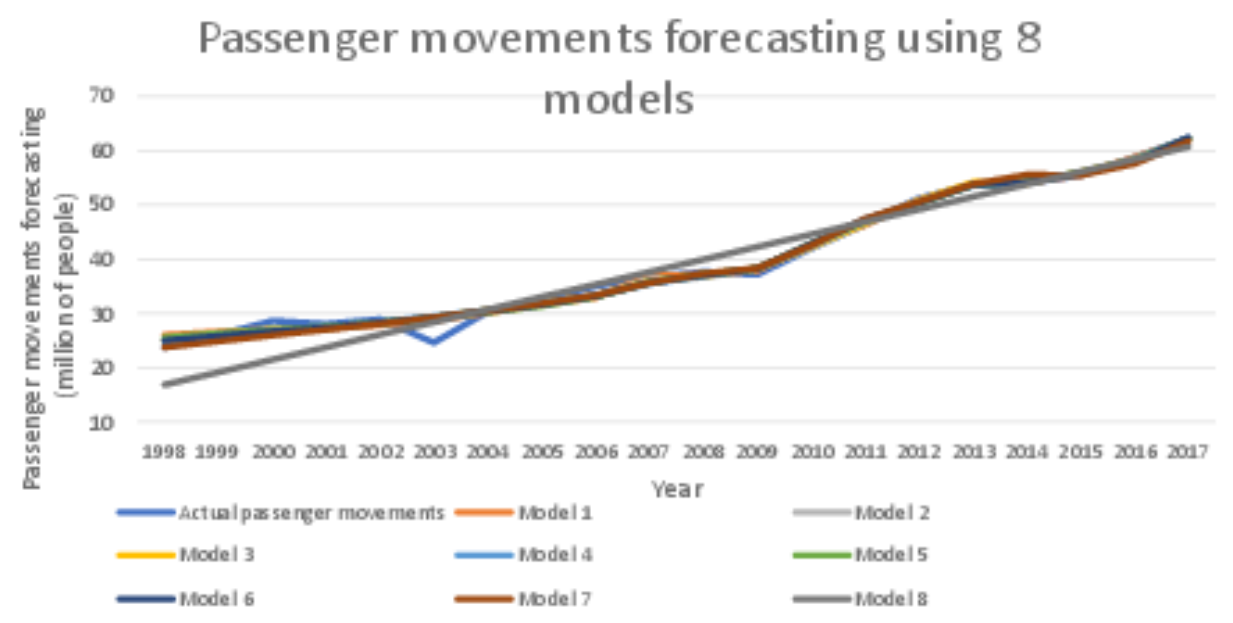

Figure 2. Passenger movements values for 1998 to 2017 using 8 different models (millions of people).

The 8 models show the trend of the passenger movements in Changi airport, but with different accuracy. Similarly, Figure 3 shows graphical representation of the error percentage for number of passenger movements in Changi airport of 8 models from 1998 to 2017. It can be observed that error percentage of each model has decreasing trend from year 1998 to 2017. Error percentages in 1998 for model 1 to model 7 are up to 9.45 $\%$, whereas in 2017 error percentages for model 1 to model 7 are up to $0.77 \%$. However, for year 2003, error percentages for 8 models are from $15.31 \%$ to $19.39 \%$, which is the largest error percentage compared to other years. This might be due to decrease of passengers travelling to Singapore caused by the outbreak of Severe Acute Respiratory Syndrome (SARS). 238 people have been infected and 33 of them died [6].

Table 1 shows average, maximum, RMS values of the errors and the values of the prioritized objective function for all models mentioned above. Model 1 has the smallest value of objective function. It shows that for accurate prediction of the air traffic, there is a need for more GDP data as an input to the model. However, from model 3 to model 1, error percentages of passenger movements do not decrease significantly. RMS errors from model 1 to model 7 increase up to $5.19 \%$, which is still 2.37 times less than RMS error for linear model.

Also, model 3 shows that it can forecast passenger movements in Changi airport with similar accuracy as model 1 and model 2, where the RMS error is less than 5\% and the average error is less than $3 \%$. In order to forecast passenger movements in Changi airport, there is a need for GDP data of 8 countries. The GDP prediction from World bank has been used for air traffic forecasting [10].

Passenger movements forecasting has been done using 8 models mentioned above. Graphical representation of forecasting the passenger movements in Changi airport from 2018 to 2023 is shown in Figure 4. Figure 4 shows that passenger movements in Changi airport will increase up to 81.65 million people by year 2023, which is $31.23 \%$ more than that in 2017. The paper proposes that model 1 to model 3 can be used to forecast passenger movements in Changi airport accurately.

Figure 5 shows a graphical representation of the ASEAN traffic on 25th October 2013. Simulation is done using traffic data from ASEAN countries. Data were collected and consolidated. The simulation was done using SAAM software. Airspace border of each ASEAN country is highlighted in black. 3D traffic densities are shown in colourful boxes. The colour tone from green to red represents the density from low to high. The light green boxes represent airways with 5 or fewer aircraft passing in 1 day. Similarly, yellow-green boxes represent airways with 6-10 aircraft, yellow boxes represent airways with 11-20 aircraft, dark yellow boxes represent airways with 21-50 aircraft, orange boxes represent airways with 51-100 aircraft and red boxes represent airways with 101-200 


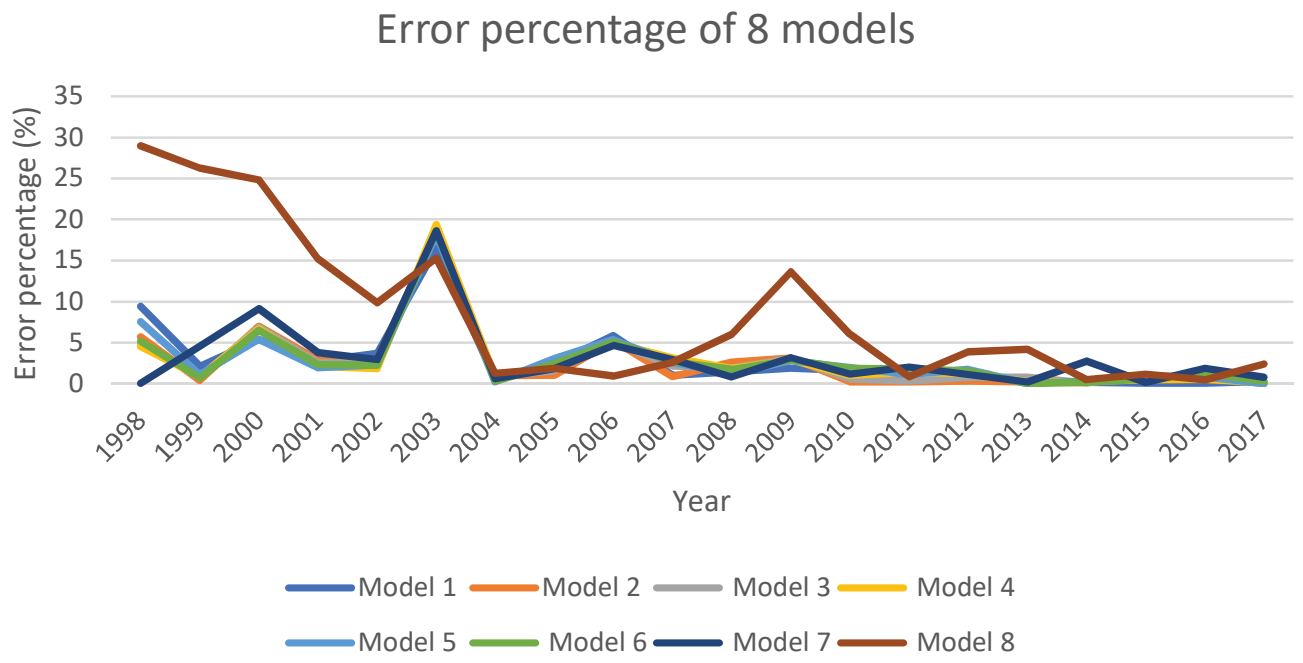

Figure 3. The error percentages of 8 models for 1998 to 2017 (in \%)

Table 1. Average, maximum and RMS errors for 8 models

\begin{tabular}{|l|l|l|l|l|l|}
\hline $\begin{array}{l}\text { Model } \\
\text { number }\end{array}$ & Model name & $\begin{array}{l}\text { Average error } \\
(\%)\end{array}$ & $\begin{array}{l}\text { Maximum } \\
\text { error }(\%)\end{array}$ & $\begin{array}{l}\text { RMS of error } \\
(\%)\end{array}$ & $\begin{array}{l}\text { Prioritized } \\
\text { objective } \\
\text { function }\end{array}$ \\
\hline 1 & With all GDP data & 2.82 & 16.52 & 4.84 & 182.84 \\
\hline 2 & $\begin{array}{l}\text { With all GDP data except } \\
\text { China }\end{array}$ & 2.70 & 18.38 & 4.93 & 213.30 \\
\hline 3 & $\begin{array}{l}\text { With all GDP data except } \\
\text { China and India }\end{array}$ & 2.78 & 18.83 & 4.95 & 219.83 \\
\hline 4 & $\begin{array}{l}\text { With all GDP data except } \\
\text { China, India and Indonesia }\end{array}$ & 2.83 & 19.4 & 5.03 & 234.39 \\
\hline 5 & $\begin{array}{l}\text { With all GDP data except } \\
\text { China, India, Indonesia and } \\
\text { Australia }\end{array}$ & 2.95 & 18.18 & 4.96 & 234.90 \\
\hline 6 & $\begin{array}{l}\text { With GDP data from Sin- } \\
\text { gapore, Malaysia, Thailand } \\
\text { and linear model }\end{array}$ & 2.92 & 18.62 & 4.94 & 244.11 \\
\hline 7 & $\begin{array}{l}\text { With GDP data from Sin- } \\
\text { gapore, India and linear } \\
\text { model }\end{array}$ & 3.17 & 18.63 & 5.19 & 301.99 \\
\hline 8 & Linear model & 8.32 & 28.98 & 12.29 & 1152.38 \\
\hline
\end{tabular}

aircraft. Most of the airspace is shown in green and yellow (no congestion), and only a few areas are shown in red and orange boxes (congestion).

Figure 6 shows a graphical representation of the ASEAN air traffic in 2021. Comparing Figure 6 with Figure 5, a significant increase in the numbers of orange and red boxes can be observed, suggesting that congested areas are expected to increase between Singapore, Kuala-Lumpur, Bangkok and Jakarta. Also, the number of flights between Singapore and China is expected to grow significantly. 


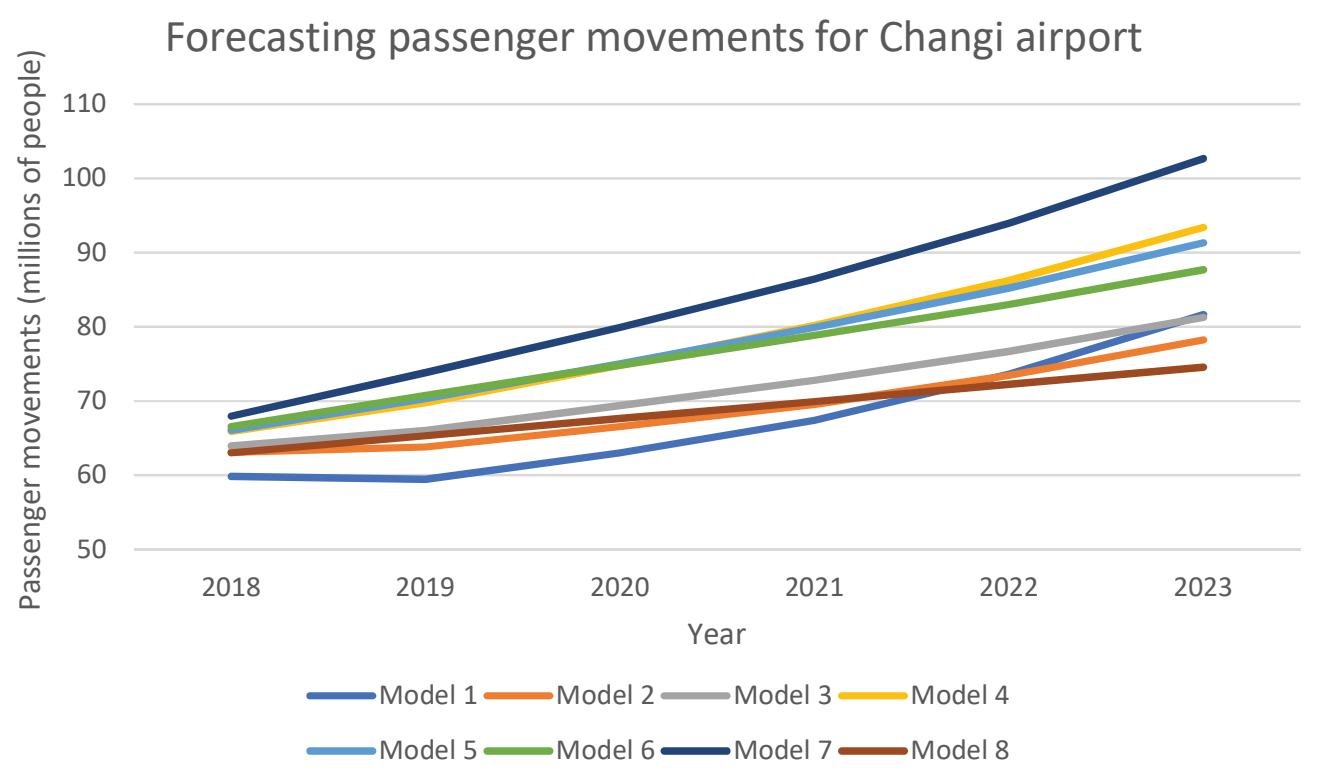

Figure 4. Forecasting passenger movements using 8 models

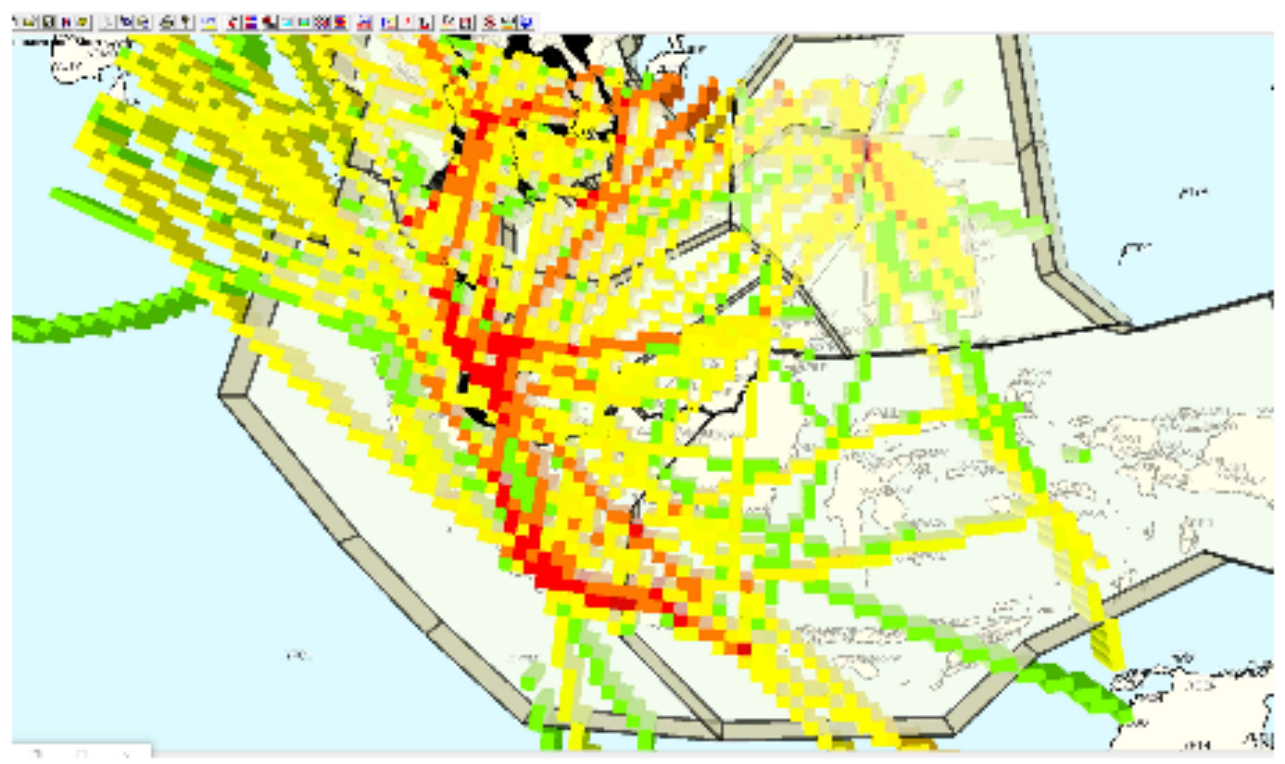

Figure 5. ASEAN traffic on 25th October 2013

Also, the proposed model is applied to forecast a city-pair and an airport-pair air traffic. Here the model is used to forecast a number of non-stop passenger aircraft between Changi airport and KLIA airport-pair and SingaporeJakarta city-pair. Formula (7) with GDP data of Singapore, China, Australia, India, Indonesia, Malaysia, Philippines and Thailand is used for forecasting numbers of passenger aircraft. The coefficients are calculated in such a way 


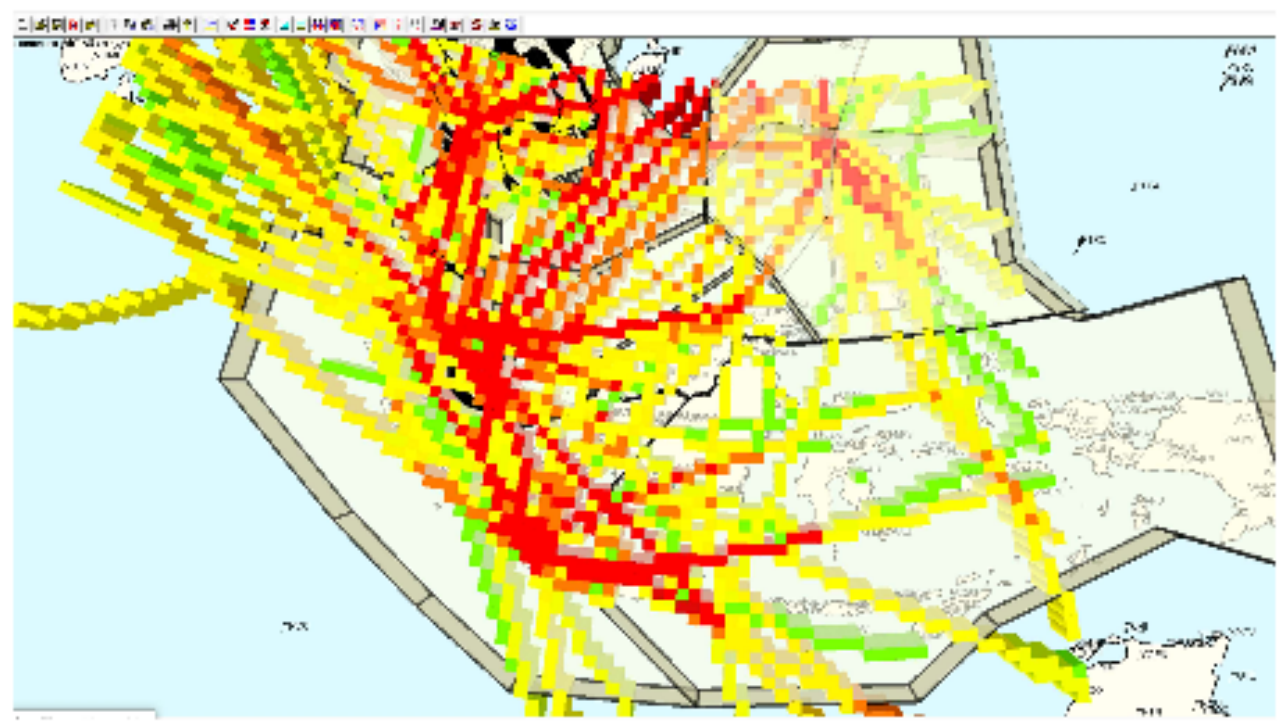

Figure 6. Forecasted ASEAN traffic for 2021

that it minimizes the objective function:

$$
\operatorname{Min} \sum_{\text {year }=2004}^{2017}(\text { year }-2003)(\text { error }[\text { year }])^{2}
$$

In order to give more importance in minimizing latest years errors rather than older years error, the objective function uses prioritized least sum of square errors, instead of the least sum of square errors.

\section{Case study 2: Forecasting the number of passenger aircraft between SingaporeCJakarta city-pair}

Numbers of passenger aircraft between Changi airport and Jakarta International airport are forecasted using 8 different models. Models have number of variables ranging from 11 to 2. - indicates where it is not applicable. The country with the lowest $B$ value is dropped in each of the following simulation until the model becomes linear. For example, model 1 is a model with all GDP data. Since, the smallest absolute value among these 7 coefficients is $B_{\text {China }}$, GDP of China is not considered in model 2. Model 2 is a model with all GDP data excluding GDP of China. In model 3, India has been dropped because $B_{\text {India }}$ has the smallest absolute value amoung $\mathrm{B}$ values in model 2. Model 3 is a model with all GDP data excluding GDP of China and India. Model 4 is a model with all GDP data except China, India and Indonesia. Model 5 is a model with all GDP data excluding GDP of China, India, Indonesia and Australia. Model 6 is a model with GDP data of Singapore, Malaysia, Thailand and linear model. Model 7 is a model with GDP data of Singapore, Thailand and linear model. Model 8 is a linear model.

Number of passenger aircraft between Changi airport and Jakarta International Airport for 8 models are compared with actual values (from Innovata) from 2004 to 2017. Numbers of passenger aircraft between Changi airport and Jakarta International airport from 2004 to 2017 using 8 models is shown in Figure 7. Graphical representation of the error percentages of 8 models for the number of passenger aircraft between Changi airport and Jakarta International airport from 2004 to 2017 is shown in Figure 8. It can be observed that the error percentage of each model has decreasing trend from year 2004 to 2017. Error percentages in 2004 for model 1 to model 8 are up to $8.88 \%$, whereas in 2017 error percentages from model 1 to model 7 are up to $1.64 \%$.

Table 2 shows average, maximum, RMS values of the errors and the value of the objective function for all models mentioned above. Model 1 has the smallest value of the objective function, whereas model 8 has the highest value 


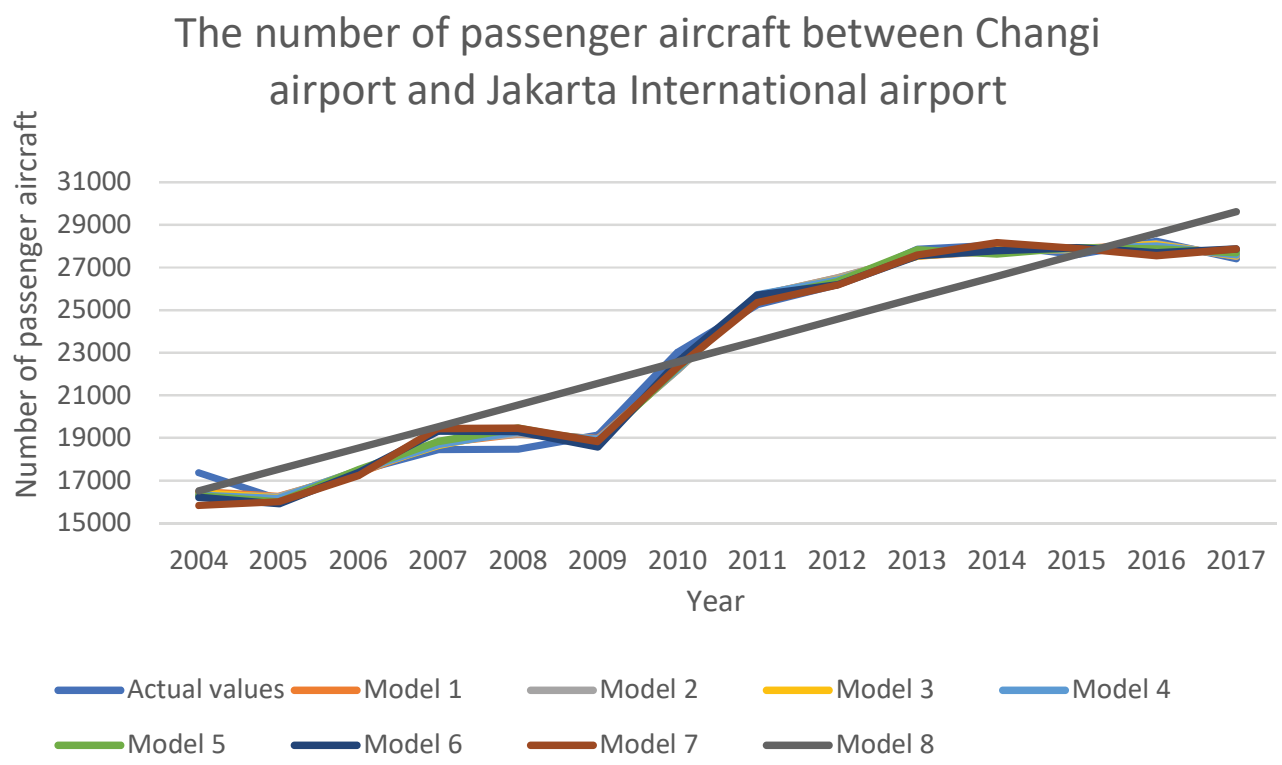

Figure 7. The number of passenger aircraft between Changi airport and Jakarta International airport

\section{The error percentages of the number of passenger aircraft}

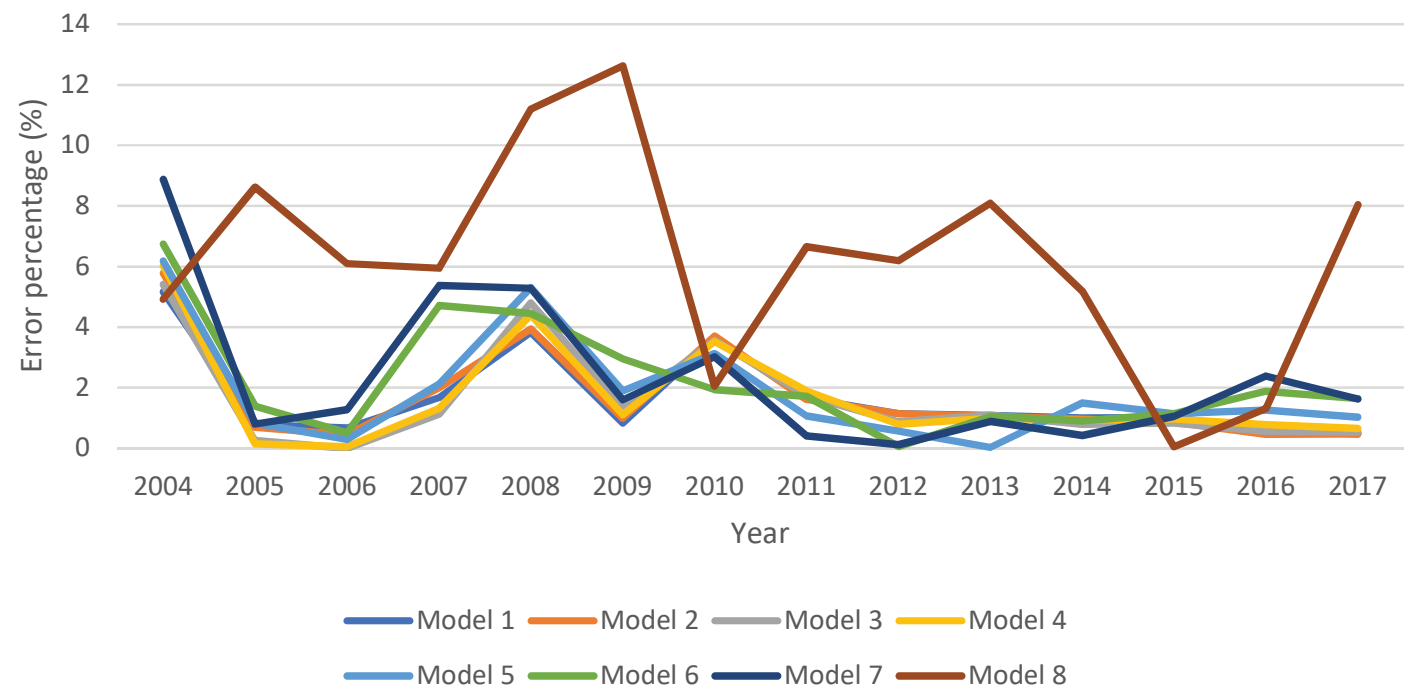

Figure 8. The error percentages of the number of passenger aircraft between Changi airport and Jakarta International airport

of the objective function. It shows that for accurate prediction of the air traffic, there is a need for more GDP data as an input to the model. However, from model 4 to model 1, error percentages of passenger aircraft do not decrease significantly, indicating that they have similar level of accuracy. Also, model 4 shows that it can forecast the number of passenger aircraft between Changi airport and Jakarta International airport with similar accuracy as from model 1 to model 3, where the RMS error is less than $2.40 \%$ and the average error is less than $1.70 \%$. RMS errors from model 1 to model 7 increase up to $2.36 \%$, which is still 3 times less than the RMS error for the linear model. 
Table 2. Average, maximum and RMS errors for different models

\begin{tabular}{|c|c|c|c|c|c|}
\hline $\begin{array}{l}\text { Model } \\
\text { number }\end{array}$ & Model name & $\begin{array}{l}\text { Average error } \\
(\%)\end{array}$ & $\begin{array}{l}\text { Maximum } \\
\text { error }(\%)\end{array}$ & $\begin{array}{l}\text { RMS of error } \\
(\%)\end{array}$ & $\begin{array}{l}\text { Prioritized } \\
\text { objective } \\
\text { function } \\
\text { (million) }\end{array}$ \\
\hline 1 & With all GDP data & 1.68 & 5.17 & 2.19 & 14.34 \\
\hline 2 & $\begin{array}{l}\text { With all GDP data exclud- } \\
\text { ing GDP of China }\end{array}$ & 1.72 & 5.78 & 2.32 & 14.53 \\
\hline 3 & $\begin{array}{l}\text { With all GDP data exclud- } \\
\text { ing GDP of China and } \\
\text { Malaysia }\end{array}$ & 1.64 & 5.41 & 2.32 & 14.86 \\
\hline 4 & $\begin{array}{l}\text { With all GDP data } \\
\text { excluding GDP of China, } \\
\text { Malaysia and Philippines }\end{array}$ & 1.69 & 6.02 & 2.38 & 15.22 \\
\hline 5 & $\begin{array}{l}\text { With all GDP data } \\
\text { excluding GDP of China, } \\
\text { Malaysia, Philippines and } \\
\text { Thailand }\end{array}$ & 1.88 & 6.18 & 2.57 & 17.73 \\
\hline 6 & $\begin{array}{l}\text { With GDP data of Singa- } \\
\text { pore, Australia, Indonesia } \\
\text { and linear model }\end{array}$ & 2.22 & 6.74 & 2.86 & 22.04 \\
\hline 7 & $\begin{array}{l}\text { With GDP data fof Singa- } \\
\text { pore, Australia and linear } \\
\text { model }\end{array}$ & 3.17 & 8.88 & 2.36 & 25.79 \\
\hline 8 & Linear model & 6.22 & 12.63 & 7.08 & 260.94 \\
\hline
\end{tabular}

Forecasting of the number of passenger aircraft is done using 8 models. Figure 9 shows graphical representation of forecasting the number of passenger aircraft between Changi airport and Jakarta International airport from 2018 to 2023. Figure 9 shows that the number of passenger aircraft will increase up to 34702 by year 2023 , which is $26.6 \%$ more than that in 2017. The project proposes that model 1 to model 4 can be used to forecast the number of passenger aircraft accurately.

\section{Case study 3: Forecasting the number of passenger aircraft between Changi airport and KLIA airport- pair}

Numbers of passenger aircraft between Changi airport and Kuala Lumpur International Airport (KLIA) are forecasted using 4 different models. The coefficient values were obtained from the optimization model using CPLEX for the number of passenger aircraft between Changi airport and KLIA, where numbers of variables have been decreased 1 by 1 . Model 1 is a model with GDP data of Singapore, Malaysia, Indonesia, China and linear model. Model 2 is a model with GDP data of Singapore, Indonesia, China and linear model. Model 3 is a model with GDP data of Singapore, China and linear model. Model 4 is a linear model.

Numbers of passenger aircraft between Changi airport and KLIA for 4 models are compared with actual values (from Innovata) for years 2004 to 2017. The numbers of passenger aircraft between Changi airport and KLIA from 2004 to 2017 using 4 models is shown in Figure 10.

Graphical representations of the error percentages for number of passenger aircraft between Changi airport and KLIA from 2004 to 2017 is shown in Figure 11. The error percentage of each model has decreasing trend from year 2004 to 2017, except year 2008. Traffic between KLIA and SG was reduced, which might be due to escape of Mas Selamat Kastari, leader of the Jemaah Islamiah (JI), the same organisation who tried to take down Yishun MRT 


\section{Forecasting of the number of passenger aircraft}

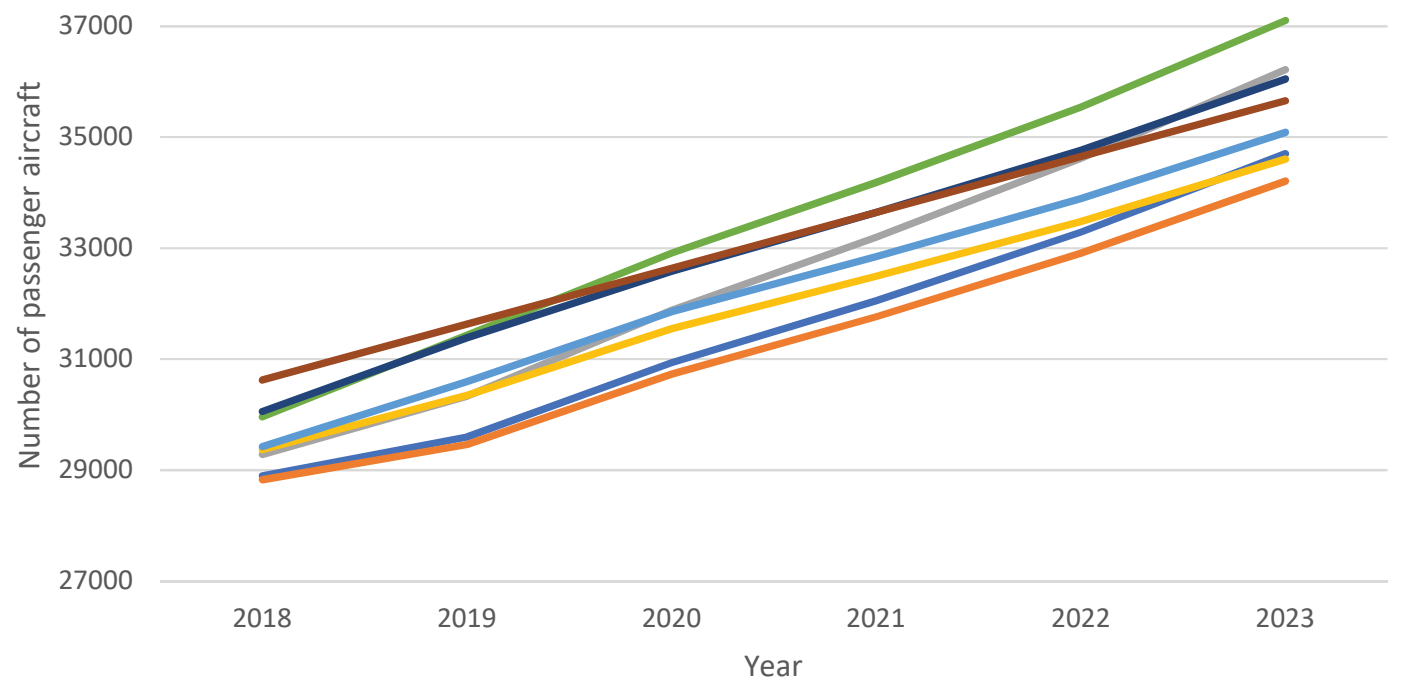

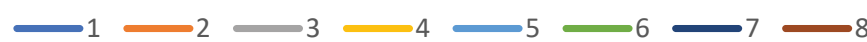

Figure 9. Forecasting of the number of passenger aircraft between Changi airport and Jakarta International airport using 8 models

Number of passenger aircraft between Changi airport and KLIA using 4 models

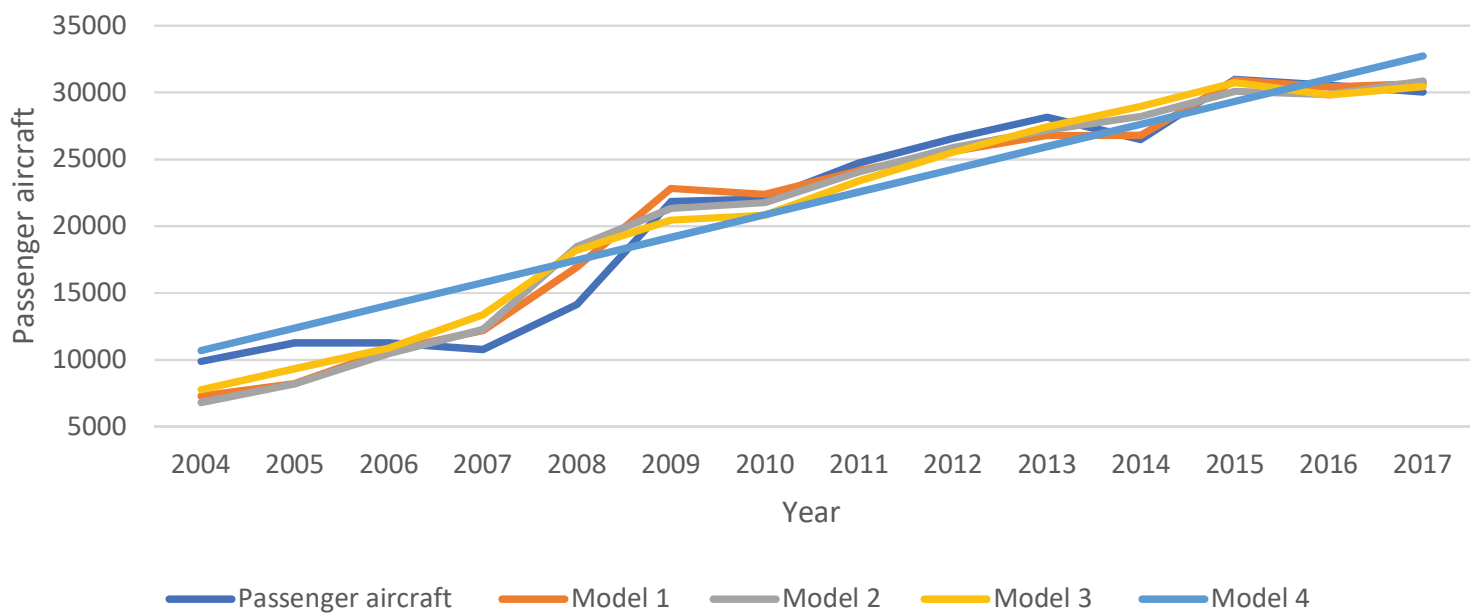

Figure 10. The number of passenger aircraft between Changi airport and KLIA 
Table 3. Average, maximum and RMS error for different models

\begin{tabular}{|l|l|l|l|l|}
\hline $\begin{array}{l}\text { Model } \\
\text { number }\end{array}$ & $\begin{array}{l}\text { Average error } \\
(\%)\end{array}$ & $\begin{array}{l}\text { Maximum } \\
\text { error }(\%)\end{array}$ & $\begin{array}{l}\text { RMS of error } \\
(\%)\end{array}$ & $\begin{array}{l}\text { Prioritized objective } \\
\text { function (million) }\end{array}$ \\
\hline 1 & 8.01 & 27.05 & 12.20 & 116.18 \\
\hline 2 & 9.80 & 31.05 & 14.65 & 211.20 \\
\hline 3 & 9.53 & 28.86 & 13.15 & 253.43 \\
\hline 4 & 12.57 & 46.54 & 16.95 & 522.53 \\
\hline
\end{tabular}

Station and several foreign embassies. There were rumours of him plotting bomb targets in Singapore and Malaysia [13]. Error percentages in 2004 for model 1 to model 4 are up to $31.05 \%$, whereas in 2017 error percentages are up to $8.98 \%$.

\section{Error percentage of the number of passenger aircraft between Changi airport and KLIA}

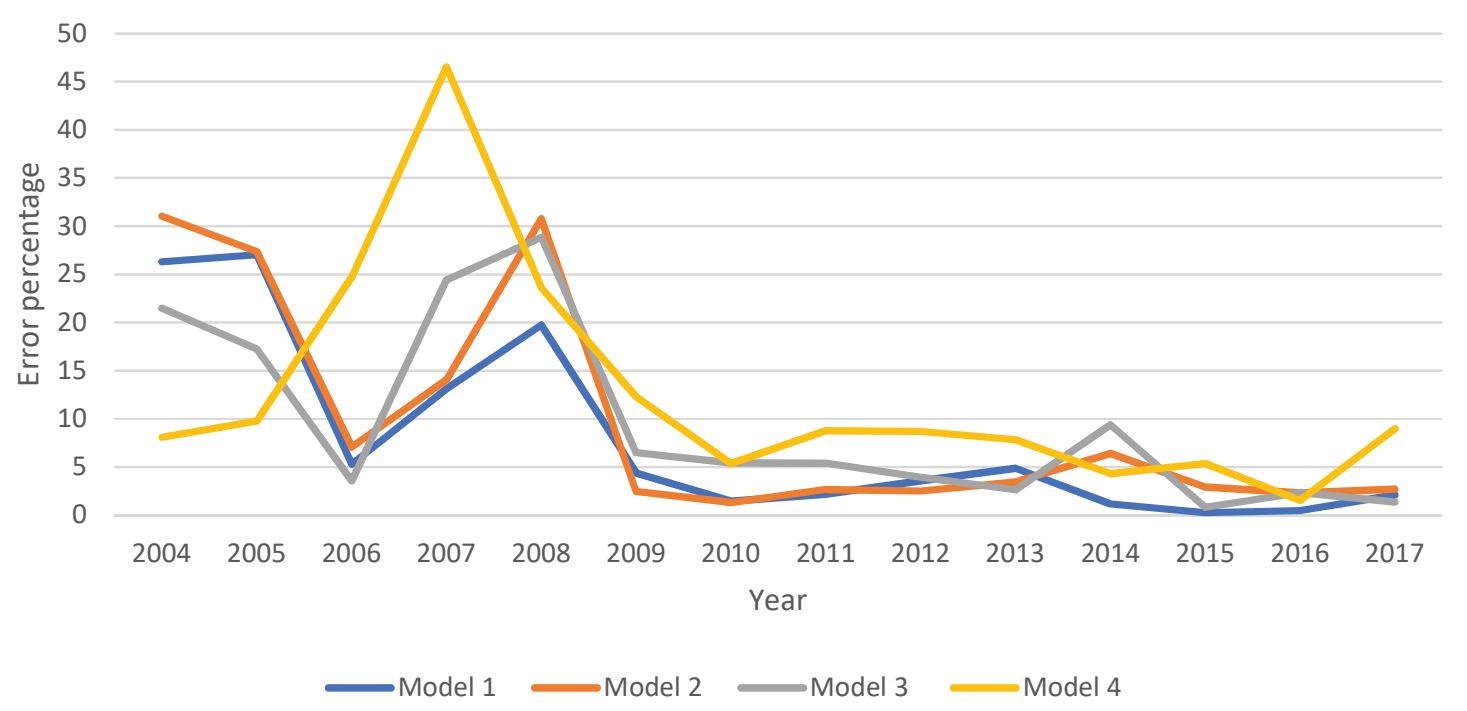

Figure 11. Error percentages of the number of passenger aircraft between Changi airport and KLIA

Table 3 shows average, maximum, RMS values of the errors and value of the objective function for all models mentioned above. Model 1 has the smallest value of the objective function, which is $45 \%$ lower than the objective function of model 2.

Forecasting of the number of passenger aircraft is done using 4 models. Figure 12 shows graphical representation of forecasting the number of passenger aircraft between Changi airport and KLIA from 2018 to 2023. According to models 1, 2 and 3, the number of passenger aircraft will be between 31698 and 40311 by year 2023.

\subsection{Advantages and limitations of the model}

1. Compared to the model proposed by Viktor Surian [26], the model described here takes into account important factors such as the economic well-being of surrounding countries. Also, Viktor Surian [20] considers only 4 variables in his model, but this research considers 11 variables initially.

2. The model can be used to forecast air traffic of any airport. A specific model can be obtained for a specific airport using optimization toolbox. An optimization toolbox finds values of coefficients of general formula using data provided. 


\section{Forecasting of the number of passenger aircraft between Changi airport and KLIA}

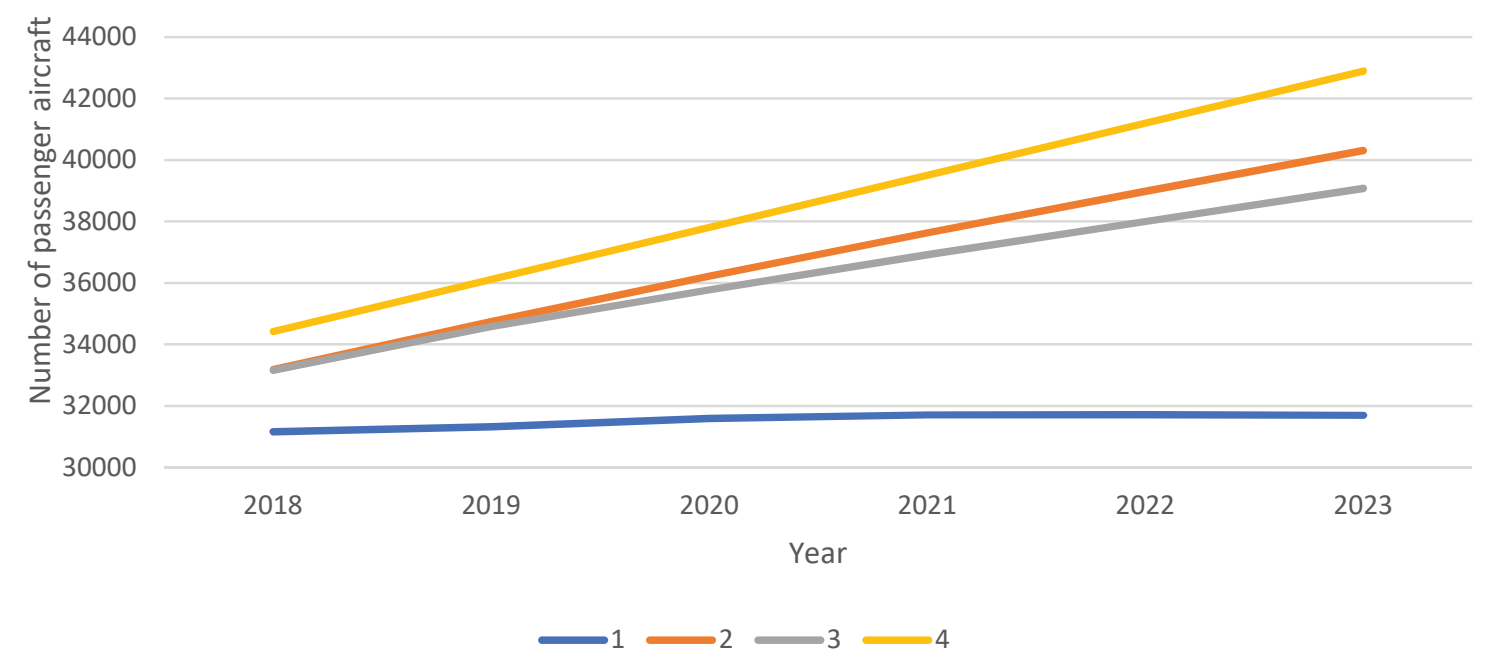

Figure 12. Forecasting of the number of passenger aircraft

3. The model provides flexibility for the user to trade-off between accuracy of forecasting to the complexity of the model. There are multiple models that can be obtained for a specific airport depending on a number of variables. The user can choose which model suits best to his requirements.

4. By using optimization to find coefficients of the model, the best fit model to the historical data has been found. In that way, it gives the least possible error of fitting. By having optimal coefficients, it gives a model with more accurate forecasting.

5. The accuracy of the forecasted GDP values of countries is unknown. Air traffic forecasting of any country is directly related to GDP of that country. That is why air traffic forecasting accuracy depends on the accuracy of forecasting of GDP values of that country and countries nearby. In case study, forecasted GDP values are taken from World Bank website.

6. Forecasting cannot be certain. Unexpected events could happen in the future, like a global crisis, some virus outbreak or war. It is very difficult to estimate effects of such unexpected events on the air traffic, which is why they are not discussed in this paper.

\section{Conclusion}

In this research the model for air traffic forecasting has been developed. The case studies were performed, and the model was validated based on low average errors and RMS errors. The model was able to forecast the country, city-pair and airport-pair air traffic. Results show that passenger forecasting for Singapore has dependence not only on that country but on neighbouring countries as well. The research predicts that the passenger movements in Changi airport will increase up to 81.65 million people by year 2023, which is $31.23 \%$ more than that in 2017 . Also, the number of passenger aircraft between Singapore and Jakarta city-pair will increase up to 34702 by year 2023, which is $26.6 \%$ more than that in 2017. In addition, the number of passenger aircraft between Changi airport and KLIA airport-pair will be between 31698 and 40311 by year 2023. It can be concluded that the accuracy of the forecasting improves with the increase of a number of neighbouring countries involved. 


\section{REFERENCES}

1. Manual on air traffic forecasting (medium and long-term forecasting). Doc. - International Civil Aviation Organization: 8991-AT/722. [Montreal] : International Civil Aviation Organization, 1972., 1972.

2. Zeliha Aka. Comparative analysis with a new hub connectivity measure considering revenue and passenger demand. Journal of Air Transport Management, 67:34 - 45, 2018.

3. W. L. Ashby. Future demand for air traffic services. Proceedings of the IEEE, 58(3):292-299, March 1970.

4. Richard T. Carson, Tolga Cenesizoglu, and Roger Parker. Forecasting (aggregate) demand for us commercial air travel. International Journal of Forecasting, 27(3):923 - 941, 2011. Special Section 1: Forecasting with Artificial Neural Networks and Computational Intelligence Special Section 2: Tourism Forecasting.

5. J. Chen, L. Chen, and D. Sun. Air traffic flow management under uncertainty using chance-constrained optimization. Transportation Research Part B: Methodological, 102:124 - 141, 2017.

6. Valerie Chew. Severe acute respiratory syndrome (sars) outbreak, 2003, 2004. Last accessed 21 June 2018.

7. Giulio Di Gravio, Maurizio Mancini, Riccardo Patriarca, and Francesco Costantino. Overall safety performance of air traffic management system: Forecasting and monitoring. Safety Science, 72:351 - 362, 2015.

8. Trading Economics. Trading economics, 2016. Last accessed 30 May 2018.

9. XIAOWEN FU, TAE HOON OUM, and ANMING ZHANG. Air transport liberalization and its impacts on airline competition and air passenger traffic. Transportation Journal, 49(4):24-41, 2010.

10. International Monetary Fund. Gdp. Last accessed 4 June 2016.

11. T. Hazledine. An augmented gravity model for forecasting passenger air traffic on city-pair routes. Journal of Transport Economics and Policy, 51(3):208-224, 2017.

12. Hashem Salarzadeh Jenatabadi and Noor Azina Ismail. Application of structural equation modelling for estimating airline performance. Journal of Air Transport Management, 40:25 - 33, 2014.

13. The Smart Local. The escape of mas selamat (27 feburary 2008). Last accessed 28 July 2018.

14. Ana M. Lopez, Mario A. Flores, and Juan I. Sanchez. Modelos de series temporales aplicados a la prediccion del trafico aeroportuario espanol de pasajeros: Un enfoque agregado y desagregado. (forecasting of spanish passenger air traffic based on time series models with aggregated and disaggregated approaches. with english summary.). Estudios de Economia Aplicada, 35(2):395 - $418,2017$.

15. Larry Meyn. Probabilistic methods for air traffic demand forecasting. AIAA Guidance, Navigation, and Control Conference and Exhibit, 5:188 - 199, 2002.

16. V.A. Profillidis. Econometric and fuzzy models for the forecast of demand in the airport of rhodes. Journal of Air Transport Management, 6(2):95-100, 2000.

17. Athina Sismanidou and Joan Tarradellas. Traffic demand forecasting and flexible planning in airport capacity expansions: Lessons from the madrid-barajas new terminal area master plan. Case Studies on Transport Policy, 5:188 - 199, 2017.

18. Tolebi Sailauov Z.W. Zhong . Air traffic forecasting using optimization for econometric models. International Conference on Engineering \& Technology, Computer, basic \& Applied Sciences, 2016.

19. Tolebi Sailauov Z.W. Zhong. Air traffic forecasting using optimization for econometric models. International Journal of Technology and Engineering Studies, 3 (5):197-203, 2017.

20. Suryan Viktor. Econometric forecasting models for air traffic passenger of indonesia. Journal of the Civil Engineering Forum, Vol 3 , Iss 1, Pp 33-44 (2017), (1):33, 2017.

21. Bogdana B. Vuji, Vukmirovi Srdan M., Goran V. Vuji, Jovii Neboja M., Jovii Gordana R., and Milun J. Babi. Experimental and artificial neural network approach for forecasting of traffic air pollution in urban areas: The case of subotica. Thermal Science, 14:S79, 2010.

22. Zia Wadud. Simultaneous modeling of passenger and cargo demand at an airport. Transportation Research Record, 2336(1):63-74, 2013.

23. S. Wenzel, Latjens K. Klker, K., and P. Bielich. Approach to forecast air-traffic movements at capacity-constrained airports. Journal of Aircraft, 52(5):1710-1714, 2015.

24. Wikipedia. Singapore changi airport, 2015. Last accessed 25 August 2016.

25. Bao Yukun, Xiong Tao, and Hu Zhongyi. Forecasting air passenger traffic by support vector machines with ensemble empirical mode decomposition and slope-based method. Discrete Dynamics in Nature and Society, Vol 2012 (2012), 2012.

26. Hong-hai Zhang, Cheng-peng Jiang, and Lei Yang. Forecasting traffic congestion status in terminal areas based on support vector machine. Advances in Mechanical Engineering, 8(9), 09 2016. Copyright - The Author(s) 2016; Last updated - 2017-01-07. 